\title{
Larval habitats and species diversity of mosquitoes (Diptera: Culicidae) in West Azerbaijan Province, Northwestern Iran
}

\author{
Mojtaba Amini ${ }^{1,2}$, Ahmad Ali Hanafi-Bojd ${ }^{3}$, Ali Ahmad Aghapour ${ }^{4}$ and Ali Reza Chavshin ${ }^{1,5^{*}}$ (1)
}

\begin{abstract}
Background: The characteristics of a larval habitat is an important factor which affects the breeding pattern and population growth of mosquitoes Information about the larval habitat characteristics and pupal productivity can be utilized for the surveillance of the level of population growth, species diversity, and preferred breeding sites of mosquitoes, which are important aspects of integrated vector control. In the present study, mosquito larvae were collected from 22 natural habitats in five counties of the West Azerbaijan Province in the Northwest of Iran during MayNovember 2018. Physicochemical characteristics of the habitats were investigated. These included alkalinity, chloride (Cl) content, water temperature $\left({ }^{\circ} \mathrm{C}\right)$, turbidity (NTU), Total Dissolved Solids (TDS) (ppm), Electrical Conductivity (EC) $(\mu \mathrm{S} / \mathrm{cm})$, and acidity $(\mathrm{pH})$. The index of affinity between the collected species was calculated using Fager \& McGowan test.

Results: A total of 2715 specimens were collected and identified. Seven different species belonging to four genera were identified in our study sites. The species included, Culex pipiens Linnaeus 1758, Culex theileri Theobald 1903, Culex mimeticus Noé 1899, Culex modestus Ficalbi 1947, Culiseta longiareolata Macquart 1838, Anopheles maculipennis Meigen 1818complex, and Aedes caspius Pallas 1771. There was a significant difference in chloride content and water temperature preferences among the different species $(P<0.05)$. Also, there was no significant difference in $\mathrm{pH}$, Alkalinity, Turbidity, TDS, and EC preferences among the different species $(P>0.05)$. The affinity between the pair of species CX. mimeticus/Cs. longiareolata was 0.526 . There was no affinity between other pairs of species or the affinity was very weak.
\end{abstract}

Conclusions: The physicochemical and biological characteristics of mosquito larval habitats play an important role in zoning of areas suitable for breeding and distribution. Surveillance of these characteristics can provide valuable information for entomological monitoring of mosquito vectors and for designing targeted control programs. Also, further studies should be undertaken in a wider geographical area, taking into account the complex characteristics of the physicochemical and ecological factors of the study area and their interaction with various mosquito species.

Keywords: Mosquito larval habitats, Oviposition sites, Species diversity

*Correspondence: chavshin@gmail.com

1 Department of Medical Entomology and Vector Control, School of Public Health and Social Determinants of Health Research Center, Urmia University of Medical Sciences, Urmia, Iran

Full list of author information is available at the end of the article

\section{Background}

The breeding pattern and population growth of medically important mosquitoes are affected by the physicochemical characteristics of their habitats. Breeding pattern and population growth surveillance is essential in designing mosquito control programs [1]. Monitoring mosquito larval habitats and population growth pattern, in the

(c) The Author(s) 2020. This article is licensed under a Creative Commons Attribution 4.0 International License, which permits use, sharing, adaptation, distribution and reproduction in any medium or format, as long as you give appropriate credit to the original author(s) and the source, provide a link to the Creative Commons licence, and indicate if changes were made. The images or other third party material in this article are included in the article's Creative Commons licence, unless indicated otherwise in a credit line to the material. If material is not included in the article's Creative Commons licence and your intended use is not permitted by statutory regulation or exceeds the permitted use, you will need to obtain permission directly from the copyright holder. To view a copy of this licence, visit http://creativeco mmons.org/licenses/by/4.0/. The Creative Commons Public Domain Dedication waiver (http://creativecommons.org/publicdomain/ zero/1.0/) applies to the data made available in this article, unless otherwise stated in a credit line to the data. 
form of studies to identify the characteristics of the habitats, can provide valuable information on mosquitoes' population growth levels, species diversity, and breeding sites for Integrated Vector Management (IVM) [2].

Vector control programs rely on the thorough knowledge of the ecology and population dynamics of mosquito species, as well as the epidemiology of mosquito-borne diseases. Therefore, research on vector habitats must be stepped up so that mosquito control programs could be carried out on sound bases [3].

The factors which affect mosquitoes' oviposition site selection, also play a crucial role in larval density and species composition $[4,5]$. In recent years, the suitable temperature $[6,7]$ and $\mathrm{pH}$ range [6] for the presence and abundance of larval species of mosquitoes have been studied and identified. Also, a direct correlation between the distribution of medically important mosquito species and physicochemical properties of their habitats, including temperature, ammonia, nitrate, $\mathrm{pH}$, dissolved oxygen, and salinity has been reported by previous studies $[8,9]$.

In different regions of the world, the influence of physicochemical properties of mosquito larval habitats on the production of emergent mosquitoes [10], their body size [10], and embryonic development and adult fitness [11] have also been studied. Moreover, it has been reported that the spatiotemporal patterns of mosquito production could be influenced by variation in the properties of breeding sites, which are important determinants of growth and survival of larval populations. Thus, the identification of these factors is essential for developing control strategies for mosquitoes [10].

Worldwide, as well as in Iran, there has been greater emphasis on the study of malaria vectors, however, most of the studies have focused on the influence of these physicochemical factors on malaria vectors $[4,12-14]$.

Only few studies have focused on the influence of these factors on mosquito larvae. In a previous study which investigated the effects of physicochemical characteristics of larval habitat waters on a broader range of mosquito genera, there was no significant difference in temperature, $\mathrm{pH}$, turbidity, electrical conductivity $(E C)$, total dissolved solids (TDS), alkalinity, total hardness, calcium, chloride, fluoride, nitrite, nitrate, phosphate, and sulphate content of the larval habitat water among the different mosquitoes species in Qom Province in the central part of Iran [15]. In another study, a positive correlation between the larval abundance of $C x$. pipiens and the physicochemical characteristics of the larval habitat including EC, alkalinity, total hardness, and chloride content. However, the negative correlation between these characteristics and larval abundance was not significant [16].
Also, the environmental changes driven by urbanization and agricultural and industrial projects affect mosquito species' diversity. Biodiversity and related important changes in geographic ranges of mosquitoes are of medical and veterinary importance, because any distributional shifts could alter and expand the range of mosquito-borne diseases [17-19].

The West Azerbaijan Province in the northwestern Iran is an important biogeographic region which shares a common border with four countries; Armenia, Azerbaijan, Iraq, and Turkey. These countries are endemic areas for a variety of mosquito species due to the presence of various environmental and geographical conditions favorable for the breeding of mosquitoes [20-23]. Consequently, there is a high diversity of mosquito species and spread of mosquito-borne diseases in the West Azerbaijan Province [24-26]. Also, this province is well-known for its abundant water resources and wetlands for migratory birds from around the world [27, 28].

By identifying the characteristics of larval habitats and species diversity of mosquitoes, the prospect and possibility of mosquito borne diseases in a particular geographical area could be determined with higher precision, and consequently, integrated vector management can be implemented with guaranteed success. The specific geographical location of the West Azerbaijan Province, its remarkable climatic diversity and abundant water resources [27], as well as the presence of a variety of mosquitoes and history of mosquito-borne diseases in this area has attracted the attention of public health research in recent years. The present study aimed to investigate (1) some of the physicochemical properties of mosquito larval habitats (temperature, $\mathrm{pH}$, turbidity, Chloride, Alkalinity, TDS and EC), (2) possible correlation between the physicochemical parameters and the presence of mosquito species, and (3) species diversity, co-occurrence and affinity index between pairs of mosquitoes species. The results of this study would be useful in determining the environmental and biological factors of the larval habitats of mosquito vectors.

\section{Methods}

\section{Study area}

The West Azerbaijan Province is located in the northwest of Iran between latitudes $39^{\circ} 46^{\prime}-35^{\circ} 7158^{\prime} \mathrm{N}$ and longitudes $44^{\circ} 3^{\prime}-47^{\circ} 23^{\prime} \mathrm{E}$. This province shares border with 4 neighboring countries: Armenia, Azerbaijan, Iraq, and Turkey (Fig. 1). This area is characterized by forest steppe with various climates, including Mediterranean hot summer climate, coastal Mediterranean climate, and the Cold Winter climate. It also has various geographical regions such as mountainous areas near 


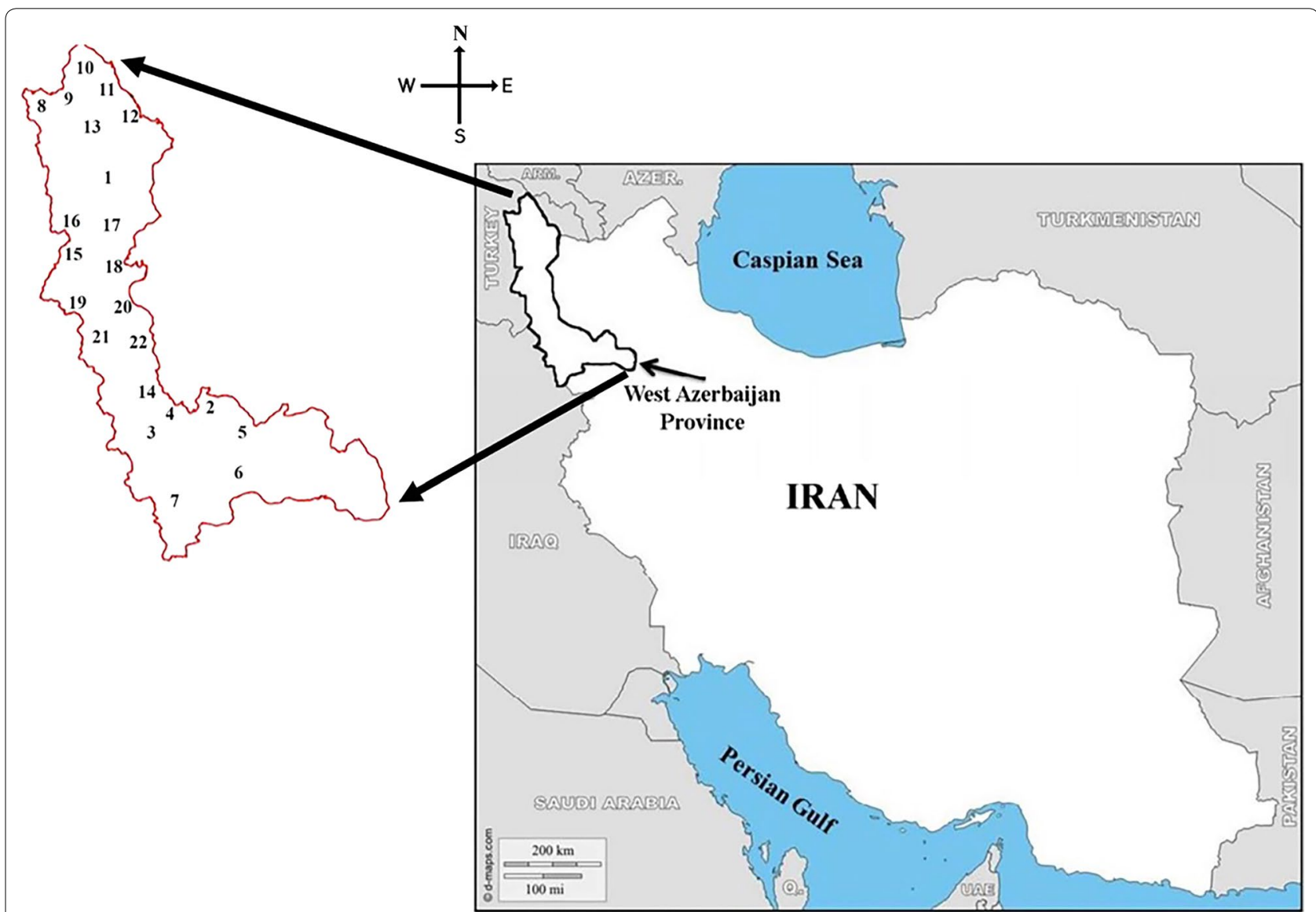

Fig. 1 Geographical location of West Azerbaijan Province in northwestern Iran and common border with different countries. Sampling sites: 1. Hashiyeh Rood, 2: Hajib Khosh, 3: Kanibrazan Wetland, 4: Khor Khoreh, 5: Gapis, 6: Beytas, 7: Mahabad, 8: Milan, 9: Sangar, 10: Sangar2, 11: Keshmesh Tappeh, 12: Deimgeshlag, 13: Glik Gadim, 14: Yadegarloo, 15: Silvana, 16: Gojar, 17: Kooraneh, 18: Ghahramanloo, 19: Mavana, 20: Shaharchay Dam, 21:Talebin, 22: NAzloo(Original basic map has been prepared from https://www.d-maps.com/)

the Iraq-Turkey border, plains near the Aras and other rivers, and the Urmia Lake coastline.

\section{Mosquito collection and identification}

Larvae were collected using the probability based sampling method [29] from natural fixed habitats in different regions of the province (with variation in climate, habitat type, etc.), so that the results can be generalized to a wide range of habitats in the province. The selected habitats included ground pools, wetlands, stream edges, riverbeds, and river edges. The standard dipping method [30] was used for collecting specimens in 22 localities of five counties on a monthly basis between May and November 2018 (Fig. 1 andTable 1). Larvae were preserved in lactophenol. Microscope slides were prepared using de Faure's medium. Third and 4th instar larvae were identified using the Iranian mosquitoes' identification keys based on morphological characteristics [31].

\section{Physicochemical analyses}

Water samples were collected from the 22 larval habitats for at least 6 times during the study period (once a month), and the water samples were kept in $1.5 \mathrm{~L}$ appropriately labeled bottles. The bottles were placed inside an icebox and were transferred to laboratory. Alkalinity, chloride $(\mathrm{Cl})$, water temperature, turbidity, Total Dissolved Solids (TDS), Electrical Conductivity (EC), and acidity $(\mathrm{pH})$ were selected because of previous scientific reports about their correlation with the presence and abundance of different species of mosquitoes and the possibility of measuring them.

The chemical factors, including alkalinity, chloride $(\mathrm{Cl})$, were analyzed based on $\mathrm{mg} / \mathrm{l}$ using standard methods [32]. The SI units for the other physicochemical parameters that were measured are as follow: water temperature $\left({ }^{\circ} \mathrm{C}\right)$, turbidity (NTU), Total Dissolved Solids (TDS) 
Table 1 The geographical properties of sampling localities

\begin{tabular}{|c|c|c|c|c|c|}
\hline County & Location & Longitude & Latitude & Altitude & Type of larval habitat \\
\hline Khoy & Hashiyeh Rood & 45.063147 & 38.571167 & 1058 & river-side \\
\hline \multirow[t]{6}{*}{ Mahabad } & Hajib Khosh & 45.797183 & 36.907883 & 1288 & canal \\
\hline & Kanibrazan Wetland & 45.764014 & 36.963683 & 1279 & wetland \\
\hline & Khor Khoreh & 45.7235 & 36.987533 & 1282 & River-side \\
\hline & Gapis & 45.747953 & 36.93805 & 1286 & Ground pool \\
\hline & Beytas & 45.694267 & 36.67645 & 1396 & stream edge \\
\hline & Mahabad & 45.722667 & 36.776683 & 1310 & dam \\
\hline \multirow[t]{6}{*}{ Makoo } & Milan & 44.427261 & 39.340794 & 1373 & canal \\
\hline & Sangar & 44.432683 & 39.317183 & 1349 & swamp \\
\hline & Sangar2 & 44.435567 & 39.3112 & 1342 & Stream edge \\
\hline & Keshmesh Tappeh & 44.400933 & 39.333514 & 1385 & Water reservoir \\
\hline & Deimgeshlag & 44.798697 & 39.624883 & 797 & Rock-pool \\
\hline & Glik Gadim & 44.667667 & 39.712636 & 807 & swamp \\
\hline Nagadeh & Yadegarloo & 45.528386 & 37.038217 & 1284 & wetland \\
\hline \multirow[t]{8}{*}{ Urmia } & Silvana & 44.851419 & 37.428667 & 1577 & River-side \\
\hline & Gojar & 44.833728 & 39.487847 & 1736 & Rock-pool \\
\hline & Kooraneh & 44.687583 & 37.7234 & 1563 & swamp \\
\hline & Gahramanloo & 45.152514 & 37.6221 & 1395 & wetland \\
\hline & Mavana & 44.796433 & 37.566583 & 1617 & Stream edge \\
\hline & Shaharchay Dam & 44.986283 & 37.4952 & 1433 & dam \\
\hline & Talebin & 44.833983 & 37.54025 & 1608 & Water reservoir \\
\hline & Nazloo & 44.985333 & 37.652683 & 1360 & canal \\
\hline
\end{tabular}

(ppm), Electrical Conductivity (EC) $(\mu \mathrm{S} / \mathrm{cm})$, and acidity $(\mathrm{pH})$. Water temperature and $\mathrm{pH}$ were measured on-site using a thermometer and $\mathrm{pH}$ probe (HANNA), respectively, and the other parameters were measured in the laboratory. Turbidity was measured using a turbidimeter device (2100P Portable Turbidimeter at Hach) and EC was measured using a conductometer device (Sension EC5 at Hach). Alkalinity and chloride content were determined using direct titration techniques. All analyses were performed according to standard methods [32].

\section{Statistical analyses}

The mean and standard deviation of each physicochemical parameter were calculated for each breeding site. The assumption of normality distribution was tested using the Kolmogorov-Smirnov test. Based on the results, the one-way ANOVA and Kruskal-wallis tests for variables with normal and non-normal distribution were used respectively for determination of probable statistical significant difference of means at 0.05 significance level, among the breeding sites. Then Post-hoc analysis were used to determine the significant difference between different points (in pairs). Dunn-Bonferroni and Ferroni tests were used for factors with non-normal and normal distribution, respectively.
The Canonical Correspondence Analysis (CCA) is used to elucidate the effects of environmental variables on the presence/abundance of species [33]. In the present study, it was used to determine the response of species composition to the studied environmental variables (CCA) [34].

\section{Indices of affinity}

The index of affinity was calculated using Fager \& McGowan test [35] to find the affinity between pairs of Culicidae species occurring in the same habitats, based on the following formula:

$$
\begin{aligned}
& {\left[J /(\mathrm{NANB})^{1 / 2}\right]-1 / 2(\mathrm{NB}) 1 / 2} \\
& I=\left[\frac{J}{(n A+n B)^{1 / 2}}\right]-\left[\frac{1}{2(n B)^{1 / 2}}\right]
\end{aligned}
$$

where the number of joint occurrences (J); the total number of occurrences of species $A(n A)$; the total number of occurrences of species $B(n B)$, and species are assigned to the letters so that $\mathrm{nA}<\mathrm{nB}$. The expressions equal to or higher than 0.5 were considered strong affinity.

Fager and McGowan [35] chose this cutoff because they felt that for species to be grouped together as cooccurring species, they should be found together in more than "half" their recorded occurrences. On the other 
hand, it is assumed that species found together in more than $50 \%$ of collection sites most probably have the same environmental needs. In other words, when one of the co-occurred species is found, it is likely that the second species is also present in the same habitat.

To evaluate the significance of this index, the " $\mathrm{t}$ " test was applied, considering an arbitrary significance level of $5 \%$. The " $\mathrm{t}$ " test was calculated according to the formula:

$$
\begin{aligned}
& t=[[(n A+n B)(2 J-1) /(2 n A n B)]-1][(n A+n B)-1]^{1 / 2} \\
& t=\left[\frac{(n B+n B)(2 J-1)}{(2 n A n B)}-1\right][\sqrt{(n A+n B-1)}]
\end{aligned}
$$

$[36,37]$.

\section{Results}

A total of 2715 mosquito specimens were collected. Seven different species belonging to four genera were identified in our study sites, including Culex pipiens Linnaeus 1758 (n: 877, 32.3\%), Culex theileri Theobald 1903, (n: 515, 18.9\%) Culex mimeticus Noé 1899, (n: 569, 20.9\%), Culex modestus Ficalbi 1947, (n: 2, 0.07\%), Culiseta longiareolata Macquart 1838, (n: 29, 2.17\%) Anopheles maculipennis Meigen 1818 complex (n: 263, 9.7\%), and Aedes caspius Pallas 1771 (n: 430, 15.8\%).

Cx. pipiens was collected from 15 (68.2\%) out of the 22 collection sites. The second most distributed species was $C x$. theileri. This species was found in 13 (59.1\%) collection sites. The distribution of the other species was as follows: An. maculipennis complex, 10 (45.5\%) sites; Ae. caspius, $6(27.3 \%)$ sites; 5 (22.7\%) collection sites for both $C x$. mimeticus and Cs. longiareolata; and Cx. modestus, 1 (4.5\%) site. In total, anopheline larvae were found in 10 sites (45.5\%), whereas culicinae larvae inhabited 22 (100\%) sites (Table 2).

The physicochemical parameters of the different collection sites and the results of Kruskal-wallis test (due to the non-normal distribution of data based on the results of Kolmogorov-smirnov test), have been presented in Table 2. Most mosquitoes' samples were collected from Silvana $(44.851419,37.428667)$ and the highest species richness was observed in Gojar (44.833728, 39.487847).

Also the results of Dunn-Bonferroni post hoc analysis revealed that the chloride content of the water collected from Hashiyeh Rood (Khoy: $44^{\circ} 58^{\prime} \mathrm{N}-38^{\circ} 32^{\prime} \mathrm{E}$ ) and Alkalinity of the water collected from Kooraneh (Urmia: $45^{\circ} 2^{\prime} \mathrm{N}-37^{\circ} 40^{\prime} \mathrm{E}$ ) were significantly higher than other localities $(\mathrm{P}<0.05)$, however, there was no significant difference in Temperature, $\mathrm{pH}$, Turbidity, TDS and EC among the different localities $(\mathrm{P}>0.05)$ (Table 2$)$.
Means and standard deviations of the physicochemical factors of the larval habitats of the different species have been shown in Table 3. The Kruskal-Wallis statistical test was used to examine the significance of the differences in each of the environmental factors in the different localities We found a significant difference in chloride content ( $p$ Value: 0.012$)$ and temperature ( $p$ Value: 0.003$)$ preference among the different species $(P<0.05)$, but the difference was not significant for $\mathrm{pH}(p$ Value: 0.576$)$, Alkalinity ( $p$ Value: 0.622$)$, Turbidity ( $p$ Value: 0.553$)$, TDS ( $p$ Value: 0.572$)$, and EC ( $p$ Value: 0.572$)(P>0.05)$.

The affinity between the pairs of species $C x$. mimeticus and Cs. longiareolata was 0.526, indicating a strong affinity. There was no affinity between the other pairs of species or the affinity was very weak; $C x$. mimeticus and Cs. longiareolata (0.526), Cs. longiareolata and An. maculipennis (0.483), Cx. theileri and An. maculipennis complex (0.475), Cx. pipiens and Ae. caspius (0.456), Cx. pipiens and $C x$. theileri (0.444), $C x$. mimeticus and An. maculipennis complex (0.441), and $C x$. theileri and $C x$. mimeticus (0.427). The affinity indices between the pairs of species have been shown in Table 4.

The species' position in space relative to the main coordinates CCA1 and CCA2 and its relationship to the direction of the gradient of the physicochemical variables have been presented in Fig. 2. The constrained inertia for the model with these variables was $27.73 \%$ for CCA2 and $32.67 \%$ for CCA1. Species-physicochemical variables interaction for all 7 variables confirmed that $\mathrm{pH}$ and turbidity for An. maculipennis, Alkalinity and Temprature for Ae. caspius, Chloride for Cx. mimeticus and Cx. modestus and EC and TDS for Cx. theileri and Cs. longiareolata were the most important factors that positively and directly correlated with their presence and abundance (Fig. 2).

\section{Discussion}

The effects of physicochemical factors of larval habitats on the distribution of mosquito larvae were examined for the first time in the west Azerbaijan Province, northwestern Iran. In this investigation, we tried to study the distribution and physicochemical factors of mosquito larval habitat in 5 counties of the West Azerbaijan Province, where various mosquito vectors of arboviruses are present. Some studies have been conducted on the fauna and checklist of mosquitoes in parts of this region [21, $38,39]$.

Canonical correspondence Analysis (CCA) of the effects of the physicochemical factors on the mosquito species showed a correlation between the presence of $C x$. pipiens and the studied environmental variables, 


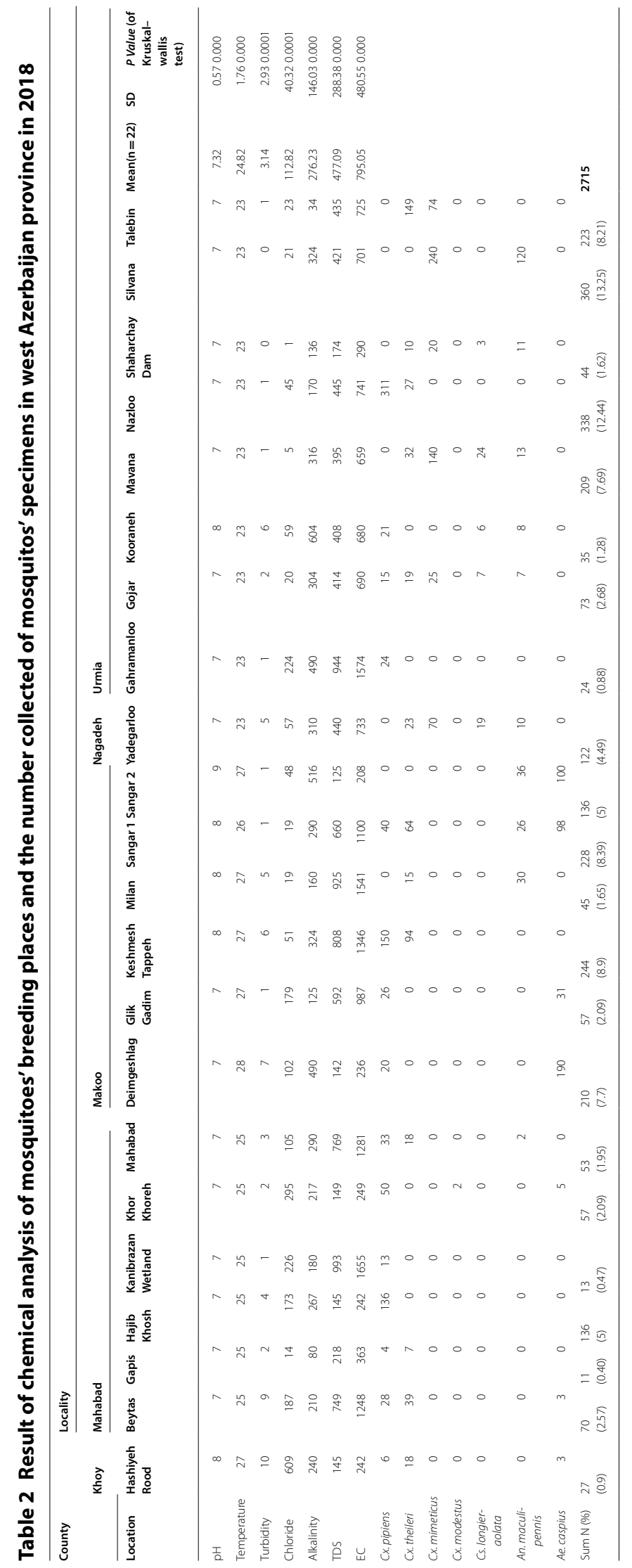


Table 3 Means of physicochemical characteristics, along with occurrence of mosquito species in different larval habitats In West Azerbaijan province in 2018

\begin{tabular}{|c|c|c|c|c|c|c|c|c|}
\hline & $\begin{array}{l}\text { Species (numbe } \\
\text { of occurrence) }\end{array}$ & $r P$ Value & & & & & & \\
\hline $\begin{array}{l}\text { Physicochemi- } \\
\text { cal param- } \\
\text { eters } \\
\text { (Mean } \pm \text { SD) }\end{array}$ & Cx.pipiens (15) & Cx. theileri (13) & Cx.mimeticus (6) & CX. modestus (1) & $\begin{array}{l}\text { Cs. longieraolata } \\
\text { (5) }\end{array}$ & $\begin{array}{l}\text { An. maculipen- } \\
\text { nis (10) }\end{array}$ & Ae. Caspius (7) & \\
\hline $\mathrm{pH}$ & $7.27 \pm 0.46$ & $7.31 \pm 0.48$ & $7.00 \pm 0.00$ & 7 & $7.20 \pm 0.45$ & $7.50 \pm 0.71$ & $7.57 \pm 0.79$ & 0.576 \\
\hline Temperature & $25.13 \pm 1.64$ & $24.62 \pm 1.71$ & $23.00 \pm 0.00$ & 25 & $23.00 \pm 0.00$ & $24.30 \pm 1.77$ & $26.43 \pm 1.13$ & 0.003 \\
\hline Turbidity & $3.73 \pm 3.10$ & $3.54 \pm 3.23$ & $1.50 \pm 1.87$ & 2 & $2.80 \pm 2.59$ & $2.40 \pm 2.22$ & $4.43 \pm 4.08$ & 0.553 \\
\hline Chloride & $153.87 \pm 153.87$ & $88.85 \pm 164.32$ & $21.17 \pm 19.78$ & 295 & $28.40 \pm 27.94$ & $35.40 \pm 31.83$ & $205.57 \pm 200.90$ & 0.012 \\
\hline Alkalinity & $285.40 \pm 144.47$ & $220.31 \pm 96.97$ & $237.33 \pm 122.50$ & 217 & $334.00 \pm 168.75$ & $325.00 \pm 141.60$ & $298.29 \pm 148.35$ & 0.622 \\
\hline TDS & $505.40 \pm 305.29$ & $505.92 \pm 254.31$ & $379.83 \pm 102.10$ & 149 & $366.20 \pm 108.68$ & $473.10 \pm 248.32$ & $366.00 \pm 285.30$ & 0.572 \\
\hline $\mathrm{EC}$ & $842.27 \pm 508.77$ & $843.00 \pm 423.60$ & $633.00 \pm 170.10$ & 249 & $610.40 \pm 181.13$ & $788.30 \pm 413.70$ & $610.00 \pm 475.48$ & 0.572 \\
\hline
\end{tabular}

which is consistent with the findings of a recent study which reported a significant positive correlation between the density of $C x$. pipiens and electrical conductivity, alkalinity, total hardness and chloride [16].

Also, the correlation of the abundance of specific species with any physicochemical factors can be one of the reasons for the selective distribution of species in specific areas and the selection of suitable habitat for oviposition. Identifying the exact effect of physicochemical factors on the presence and abundance of mosquito larvae in different habitats seems to be a complex process and highly dependent on the characteristics of any specific species and related factors such as the pattern of chemical use in the environment (such as pesticides). Some of the physicochemical parameters could be used as a source of energy to expand the distribution of algae and other organisms (including bacteria) that function as key food for larvae [40], and to provide chemical stimuli for females to select a suitable oviposition site and trigger egg hatching [41].

However, the results of a recent study in Iran showed no significant correlation between the abundance of larvae and the studied different physicochemical and microbial parameters [15].

Water temperature acts as one of the most important factors affecting the establishment and growth of some of mosquito larvae in larval habitats [42]. Turbidity has also been reported to affect water temperature [43]. Based on the results of previous studies and due to the high correlation between some physicochemical factors and larval abundance of some species, it has been suggested that these factors be used as predictors of the presence of species in the environment, e.g. salinity and DO for Culex pipiens and Cx. perexiguus [9].

The distribution of mosquito species could be affected by various environmental factors such as physicochemical factors of their breeding places in the larvae stage, interspecific association, and climate [44].

In addition to biological curiosity and biodiversity, any change in the diversity and population of vector mosquitoes can affect the transmission cycle and burden of related diseases. As previously reported, global warming can increase the potential for transmission of mosquitoborne diseases [45]. Also previous studies have suggested that complex interactions exist between environmental factors and abundance of mosquito species, which necessitates time-dependent and species-specific control programs [46]. In particular, regular and accurate monitoring of the status of important medical mosquitoes, factors affecting their distribution and population, and prediction of their control strategies in specific conditions for sensitive region such as West Azerbaijan province is of particular importance, due to its border with four neighboring countries, presence of a variety of climatic conditions, and history of mosquito-borne diseases.

The species identified in this study can transmit important pathogens. Diseases such as lymphatic filariasis [47], and arboviruses [48] can be transmitted by different species of Culex mosquitoes. Ae. caspius infection with West Nile fever virus has already been demonstrated in our study area [25]. An. maculipennis, which is one of the important vectors of malaria [49], is of medical importance with a history of transmission in the region. Finally Cs. longiareolata acts as the vector of some infectious diseases such as the avian malaria [50,51], tularemia [52], and arboviruses like West Nile fever [53-55].

A recent study [56,57] reported the presence of five of the species identified in our study, including $A n$. maculipennis, Cx. pipiens, Cx. theileri, Cs. longiareolata and Ae. caspius in the East Azerbaijan province. Also, another study reported the presence of $\mathrm{An}$. maculipennis, Cx.pipiens, Cx. theileri, and Cs. longiareolata) 
Table 4 Percent of co-occurrence and affinity index between pairs of culicidae species in visited breeding places of the study area, west Azerbaijan province in Iran during 2018

\begin{tabular}{|c|c|c|c|c|c|c|c|}
\hline Species & Cx. pipiens & Cx. theileri & Cx. mimeticus & Cx. modestus & Cs. longieraolata & An. maculipennis & Ae. caspius \\
\hline Cx.pipiens & * & 28.6 & 4.8 & 6.3 & 10 & 16 & 27.3 \\
\hline Cx. theileri & 0.444 & * & 26.3 & 0 & 22.2 & 30.4 & 15 \\
\hline Cx.mimeticus & -0.024 & 0.427 & * & 0 & 36.4 & 31.3 & 0 \\
\hline CX.modestus & 0.129 & -0.139 & -0.204 & $*$ & 0 & 0 & 12.5 \\
\hline Cs. longieraolata & 0.102 & 0.357 & 0.526 & -0.5 & $*$ & 33.3 & 0 \\
\hline An. maculipennis & 0.197 & 0.475 & 0.441 & -0.5 & 0.483 & * & 11.8 \\
\hline Ae. caspius & 0.456 & 0.176 & -0.204 & -0.122 & -0.224 & 0.081 & * \\
\hline
\end{tabular}

The bold italic value indicates the highest affinity between the studied species (Cs. longiareolata and Cx. mimeticus)

The italic values of affinity between the pairs of species indicates the highest values between the studied pairs of species respectively

in Zanjan Province, which were also identified in our study [58]. Moreover, another study conducted in Kurdistan Province [59] reported the occurrence of six species, including An. maculipennis, Cx. theileri, Cx. pipiens, $C x$. mimeticus, Cs. longiareolata, and Ae. caspius, which were also present in our study region. In the Kurdistan and East Azarbaijan provinces, $C x$. theileri and $C x$. pipiens were the most dominant species, which is similar to the findings of the present study. Our results show that $C x$. theileri (10 sites) and $C x$. pipiens (13 sites) were the most dominant species in the province.

A significant difference was observed between the density of An. culicifacies and calcium and EC content, and between An. turkhudi and An. superpictus and total hardness in Sistan and Baluchestan Province of Iran [12]. The authors indicated that the larvae of An. culicifacies and An. turkhudi are more sensitive to physicochemical factors in different habitats compared with other species, which may explain the limited spread of

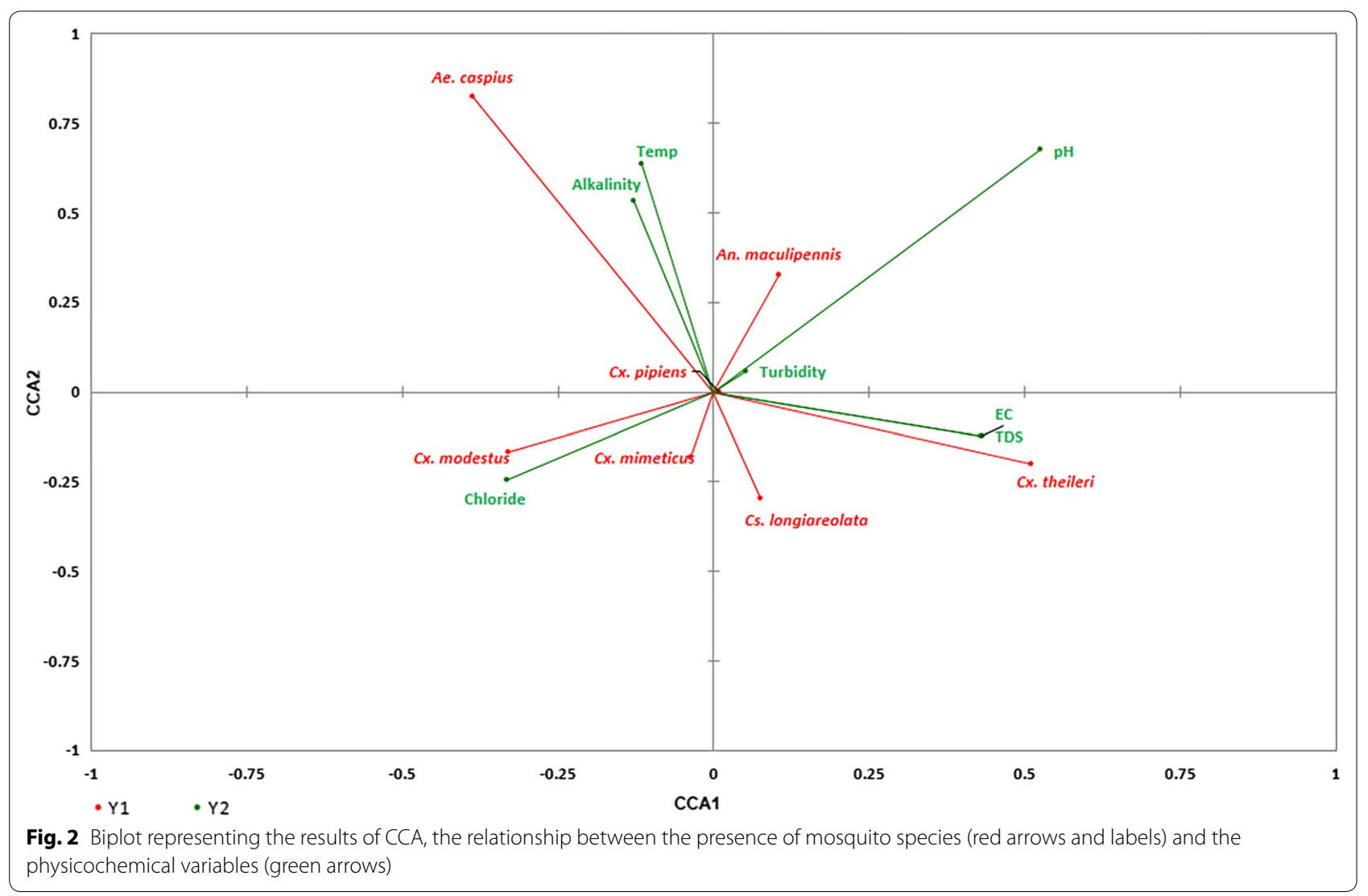


the species in this region. Nikookar et al. [16] showed that positive correlation exists between the larval abundance of Cx. pipiens and physicochemical characteristics such as EC, alkalinity, total hardness, and chloride. However, Abai et al. [15] demonstrated that there was no significant differences in physicochemical and microbial parameter preferences among the different species, and that there was no significant correlation between the abundance of larvae and the different physicochemical and microbial parameters. Also for anopheline species, the significant effects of conductivity, total alkalinity, sulphate and chloride on their distribution and abundance have been reported [60].

Based on the results of the current study, there was a strong affinity between $C x$. mimeticus and Cs. longiareolata (index 0.5 ), but in a previous studies, no significant correlation between the presence of these two species was found [16, 61]. The difference in the results of the present study with the previous study may be due to differences in the specific environmental conditions of each region and the interaction of complex conditions in addition to the physicochemical properties of the environment with the mosquito larvae. Based on our affinity index analysis, there was no correlation between the other species which may be due to the different requirements of these species. In a recent study in southern Iran [4], a significant correlation between the following species was found: An. Culicifacies/An. stephensi and An. dthali, An. dthali/An. stephensi (Index >0.5),. An. dthali/ An. superpictus and An. moghulensis, and An. moghulensis/An.superpictus. Based on the affinity index of the above study, there was no correlation between An. apoci and other species.

Considering the limitations of this study, future studies should focus on a wider geographical area and the use of accurate methods for collecting mosquito larvae in order to provide evidence-based contributions to the integrated vector management.

As a limitation, in the current study, samples were collected from the same breeding site over time, pseudoreplication should be assumed and proper models such as the LMEM model should be used for future experiments to evaluate the fixed effect, the random effect and even the response variable. Also, using more accurate statistical analysis for evaluating the correlation between physicochemical factors and the presence and abundance of mosquitoes will lead to more valuable and accurate information.

\section{Conclusions}

Due to the considerable climatic and environmental variability affecting the establishment and spread of mosquitoes (especially diseases' vector species) in different regions of Iran, and in particular, in the study area, the results of the present study, will be useful in determining the environmental and biological factors of the larval habitats of medically important mosquitoes. Consequently, identification of environmental factors affecting the breeding of mosquitoes can help in the mapping and prediction of oviposition site selection and distribution of these vectors and pave way for the development of entomological monitoring and targeted control programs for controlling the vectors with higher accuracy.

\section{Abbreviations \\ NTU: Turbidity; TDS: Total Dissolved Solids; EC: Electrical Conductivity; pH: Acidity.}

\section{Acknowledgements}

This article is part of the results of the first author's dissertation for fulfillment of MSc degree in Medical Entomology and Vector Control from the Department of Medical Entomology and Vector Control, School of Public Health, Urmia University of Medical Sciences (UMSU), Urmia, Iran. The authors are grateful to Dr. Cyrus Alinia (Department of Management Science and Health Economics, School of Public Health, UMSU) for his help in statistical analysis. This study was supported by the Urmia University of Medical Sciences (UMSU), Urmia, Iran (project no. 1579).

\section{Authors' contributions}

ARC designed and supervised the study, MA and AAA did the field and laboratory activities. Also, MA and AAHB wrote the draft of manuscript and ARC finalized the Draft. All authors reviewed and approved the final version of manuscript for publication. All authors read and approved the final manuscript.

\section{Funding}

This study was financially supported by the Urmia University of Medical Sciences (UMSU), Urmia, Iran (Project no. 1579). The funder had no role in data collection, analysis, interpretation and presentation.

\section{Availability of data and materials}

The datasets used and/or analyzed during the current study are available from the corresponding author on reasonable request.

Ethics approval and consent to participate

This project has been approved by University Ethic Committee of Urmia University of Medical Sciences.

\section{Consent for publication}

Not applicable.

\section{Competing interests}

The authors declare that they have no competing interests.

\section{Author details}

${ }^{1}$ Department of Medical Entomology and Vector Control, School of Public Health and Social Determinants of Health Research Center, Urmia University of Medical Sciences, Urmia, Iran. ${ }^{2}$ Student Research Committee, Urmia University of Medical Sciences, Urmia, Iran. ${ }^{3}$ Department of Medical Entomology and Vector Control, School of Public Health, Tehran University of Medical Sciences, Tehran, Iran. ${ }^{4}$ Department of Environmental Health Engineering, School of Public Health, Urmia University of Medical Sciences, Urmia, Iran.

${ }^{5}$ Social Determinants of Health Research Center, Urmia University of Medical Sciences, Urmia, Iran.

Received: 15 April 2020 Accepted: 10 November 2020

Published online: 19 November 2020 


\section{References}

1. Manguin S, Boëte C: Global impact of mosquito biodiversity, human vector-borne diseases and environmental change. The Importance of Biological Interactions in the Study of Biodiversity InTech 2011

2. Piyaratne MK, Amerasinghe FP, Amerasinghe PH, Konradsen F. Physicochemical characteristics of Anopheles culicifacies and Anopheles varuna breeding water in a dry zone stream in Sri Lanka. J Vector Borne Diseases. 2005;42(2):61

3. Organization WH: Manual on environmental management for mosquito control, with special emphasis on malaria vectors: World Health Organization; 1982.

4. Hanafi-Bojd A, Vatandoost H, Oshaghi M, Charrahy Z, Haghdoost A, Sedaghat M, Abedi F, Soltani M, Raeisi A. Larval habitats and biodiversity of anopheline mosquitoes (Diptera: Culicidae) in a malarious area of southern Iran. J Vector Borne Diseases. 2012;49(2):91.

5. Nikookar S, Fazeli-Dinan M, Azari-Hamidian S, Mousavinasab S, Arabi M, Ziapour S, Shojaee J, Enayati A. Species composition and abundance of mosquito larvae in relation with their habitat characteristics in Mazandaran Province, northern Iran. Bull Entomol Res. 2017:107(5):598-610.

6. Clements AN: The biology of mosquitoes. Volume 1: development, nutrition and reproduction: Chapman \& Hall; 1992.

7. Muirhead-Thomson RC: Mosquito behaviour in relation to malaria transmission and control in the tropics. Mosquito Behaviour in relation to Malaria Transmission and Control in the Tropics 1951.

8. Ibrahim AEA, El-Monairy OM, El-Sayed YA, Baz MM. Mosquito breeding sources in Qalyubiya Governorate Egypt. Egyptian Academic J Biol Sci E Medical Entomol Parasitol. 2011;3(1):25-39.

9. Kenawy M, Ammar S, Abdel-Rahman H. Physico-chemical characteristics of the mosquito breeding water in two urban areas of Cairo Governorate, Egypt. J Entomol Acarological Res. 2013;45(3):e17.

10. Mwangangi JM, Mbogo CM, Muturi EJ, Nzovu JG, Kabiru EW, Githure $J$, Novak RJ, Beier JC. Influence of biological and physicochemical characteristics of larval habitats on the body size of Anopheles gambiae mosquitoes (Diptera: Culicidae) along the Kenyan coast. J Vector Borne Diseases. 2007:44(2):122.

11. Hyelemad A, Kayode OI, Christian UA, Abdulazeez AK, Moses OO. Evaluation of critical larval habitat physico-chemical factors on embryonic development and adult fitness of Culex quinquefasciatus mosquitoes (Diptera: Culicidae). Malaya J Biosci. 2018;5(2):48-56.

12. Ghanbari M, RAKHSH KA, Salehi M, HASANZEHI A: The study of physical and chemical factors affecting breeding places of Anopheles in Iranshahr. 2005.

13. Soleimani-Ahmadi M, Vatandoost $H$, Hanafi-Bojd A-A, Zare M, Safari $R$, Mojahedi A, Poorahmad-Garbandi F. Environmental characteristics of anopheline mosquito larval habitats in a malaria endemic area in Iran. Asian Pacific Journal Tropical Med. 2013;6(7):510-5.

14. Yaghoobi-Ershadi M, Namazi J, Piazak N. Bionomics of Anopheles sacharovi in Ardebil province, northwestern Iran during a larval control program. Acta Trop. 2001;78(3):207-15

15. Abai MR, Saghafipour A, Ladonni H, Jesri N, Omidi S, Azari-Hamidian S. Physicochemical characteristics of larval habitat waters of mosquitoes (Diptera: Culicidae) in Qom Province, central Iran. J Arthropod Borne Diseases. 2016;10(1):65.

16. Nikookar SH, Fazeli-Dinan M, Azari-Hamidian S, Mousavinasab SN, Aarabi M, Ziapour SP, Esfandyari Y, Enayati A. Correlation between mosquito larval density and their habitat physicochemical characteristics in Mazandaran Province, northern Iran. PLoS Neglected Tropical Diseases. 2017;11(8):e0005835.

17. Kilpatrick AM, Randolph SE. Drivers, dynamics, and control of emerging vector-borne zoonotic diseases. Lancet. 2012;380(9857):1946-55.

18. Githeko AK, Lindsay SW, Confalonieri UE, Patz JA. Climate change and vector-borne diseases: a regional analysis. Bull World Health Organ. 2000;78:1136-47.

19. Siraj A, Santos-Vega M, Bouma M, Yadeta D, Carrascal DR, Pascual M. Altitudinal changes in malaria incidence in highlands of Ethiopia and Colombia. Science. 2014;343(6175):1154-8

20. Abai M, Azari-Hamidian S, Ladonni H, Hakimi M, Mashhadi-Esmail K, Sheikhzadeh K, Kousha A, Vatandoost H. Fauna and checklist of mosquitoes (Diptera: Culicidae) of East Azerbaijan Province, northwestern Iran. J Arthropod-borne Diseases. 2007;1(2):27-33.
21. Amini M, Hanafi-Bojd AA, Asghari S, Chavshin AR. The Potential of West Nile Virus Transmission Regarding the Environmental Factors Using Geographic Information System (GIS), West Azerbaijan Province Iran. J Arthropod-borne Diseases. 2019;13(1):27.

22. Terenius $\mathrm{O}$, Lindh JM, Eriksson-Gonzales $\mathrm{K}$, Bussière $L$, Laugen AT, Bergquist $\mathrm{H}$, Titanji K, Faye I. Midgut bacterial dynamics in Aedes aegypti. FEMS Microbiol Ecol. 2012:80(3):556-65.

23. Rani A, Sharma A, Rajagopal R, Adak T, Bhatnagar RK. Bacterial diversity analysis of larvae and adult midgut microflora using culture-dependent and culture-independent methods in lab-reared and field-collected Anopheles stephensi-an Asian malarial vector. BMC Microbiol. 2009;9(1):96.

24. Azari-Hamidian S, Yaghoobi-Ershadi M, Javadian E, Abai M, Mobedi I, Linton YM, Harbach R. Distribution and ecology of mosquitoes in a focus of dirofilariasis in northwestern Iran, with the first finding of filarial larvae in naturally infected local mosquitoes. Med Vet Entomol. 2009;23(2):111-21.

25. Bagheri M, Terenius O, Oshaghi MA, Motazakker M, Asgari S, Dabiri F, Vatandoost H, Mohammadi Bavani M, Chavshin AR. West Nile virus in mosquitoes of Iranian wetlands. Vector-Borne Zoonotic Diseases. 2015:15(12):750-4.

26. Vatandoost $\mathrm{H}$, Ashraf H, Lak SS, Mahdi RE, Abai M, Nazari M. Factors involved in the re-emergence of malaria in borderline of Iran, Armenia, Azerbaijan and Turkey. Southeast Asian J Trop Med Public Health. 2003;34:6-14

27. Salmanzadeh R, Majidi A, Jabbari H, Abbasnejad H, Saket A: The Study of Mahabad, s Kanibarazan Wetland Biodiversity Indexes, IRAN. In: Inter Conf Biol Environ Chem IPCBEE, IACSIT Press, Singapore: 2011. 73-77.

28. John R. "Birds of Azerbaijan" by Michael Patrikeev [book review]. Canadian Field Naturalist. 2005;119(2):299.

29. Levy PS, Lemeshow S: Sampling of populations: methods and applications: John Wiley \& Sons; 2013

30. Silver JB: Mosquito Ecology-Field Sampling Methods 3rd Edition; 2008.

31. Azari-Hamidian S, Harbach RE. Keys to the adult females and fourthinstar larvae of the mosquitoes of Iran (Diptera: Culicidae). Zootaxa. 2009;2078(1):1-33.

32. Miller T. Paratransgenesis as a potential tool for pest control: review of applied arthropod symbiosis. J Appl Entomol. 2011;135(7):474-8.

33. Ter Braak CJ. Canonical correspondence analysis: a new eigenvec tor technique for multivariate direct gradient analysis. Ecology. 1986:67(5):1167-79.

34. Medeiros-Sousa AR, de Oliveira-Christe R, Camargo AA, Scinachi CA, Milani GM, Urbinatti PR, Natal D, Ceretti-Junior W, Marrelli MT. Influence of water's physical and chemical parameters on mosquito (Diptera: Culicidae) assemblages in larval habitats in urban parks of São Paulo Brazil. Acta Tropica. 2020;205:105394.

35. Fager EW, McGowan JA. Zooplankton species groups in the North Pacific. Science. 1963;140(3566):453-60.

36. Alencar J, dos Santos Silva J, Serra-Freire NM, Guimarães AÉ: Dispersion and Ecological Plasticity Patterns of Haemagogus capricornii and H. janthinomys (Diptera: Culicidae) Populations in Different Regions of Brazil1. Entomological News 2009, 120(1):53-60.

37. Southwood TRE, Henderson PA: Ecological methods: John Wiley \& Sons; 2009

38. Khoshdel-Nezamiha F, Vatandoost H, Azari-Hamidian S, Bavani MM, Dabiri F, Entezar-Mahdi R, Chavshin AR. Fauna and larval habitats of mosquitoes (Diptera: Culicidae) of West Azerbaijan Province, northwestern Iran. J Arthropod Borne Dis. 2014;8(2):163.

39. Khoshdel-Nezamiha F, Vatandoost H, Oshaghi MA, Azari-Hamidian S, Mianroodi RA, Dabiri F, Bagheri M, Terenius O, Chavshin AR. Molecular characterization of mosquitoes (Diptera: Culicidae) in Northwestern Iran by using rDNA-ITS2. Japanese J Infectious Diseases. 2016;69(4):319-22.

40. Kibuthu TW, Njenga SM, Mbugua AK, Muturi EJ. Agricultural chemicals: life changer for mosquito vectors in agricultural landscapes? Parasites Vectors. 2016;9(1):500.

41. Noori N, Lockaby BG, Kalin L. Larval development of Culex quinquefasciatus in water with low to moderate. J Vector Ecol. 2015:40(2):208-20.

42. Bayoh MN, Lindsay SW. Temperature-related duration of aquatic stages of the Afrotropical malaria vector mosquito Anopheles gambiae in the laboratory. Med Vet Entomol. 2004;18(2):174-9. 
43. Paaijmans K, Takken W, Githeko A, Jacobs A. The effect of water turbidity on the near-surface water temperature of larval habitats of the malaria mosquito Anopheles gambiae. Int J Biometeorol. 2008;52(8):747-53.

44. Okogun GR, Anosike JC, Okere A, Nwoke B, Esekhegbe A. Epidemiological implications of preferences of breeding sites of mosquito speciesin Midwestern Nigeria. Ann Agric Environ Med. 2003;10(2):217-22.

45. Hanafi-Bojd AA, Sedaghat MM, Vatandoost H, Azari-Hamidian S, Pakdad K: Predicting environmentally suitable areas for Anopheles superpictus Grassi (sl), Anopheles maculipennis Meigen (sl.) and Anopheles sacharovi Favre (Diptera: Culicidae) in Iran. Parasites \& vectors 2018, 11(1):382.

46. Coutinho-Abreu IV, Zhu KY, Ramalho-Ortigao M. Transgenesis and paratransgenesis to control insect-borne diseases: current status and future challenges. Parasitol Int. 2010;59(1):1-8.

47. Nchoutpouen E, Talipouo A, Djiappi-Tchamen B, Djamouko-Djonkam L, Kopya E, Ngadjeu CS, Doumbe-Belisse P, Awono-Ambene P, Kekeunou S, Wondji CS. Culex species diversity, susceptibility to insecticides and role as potential vector of lymphatic filariasis in the city of Yaoundé, Cameroon. PLoS Neglected Tropical Diseases. 2019;13(4):e0007229.

48. Turell MJ. Members of the Culex pipiens complex as vectors of viruses 1. J American Mosquito Control Association. 2012:28(4s):123-6.

49. Hanafi-Bojd AA, Azari-Hamidian S, Hassan V, Zabihollah C. Spatio-temporal distribution of malaria vectors (Diptera: Culicidae) across different climatic zones of Iran. Asian Pacific J Tropical Med. 2011;4(6):498-504.

50. Huff CGJEp: Susceptibility of mosquitoes to avian malaria. 1965, 16(1):107-132.

51. Schoener E, Uebleis SS, Butter J, Nawratil M, Cuk C, Flechl E, Kothmayer M, Obwaller AG, Zechmeister T, Rubel T. Avian Plasmodium in Eastern Austrian mosquitoes. Malaria J. 2017;16(1):389.

52. Maslov AVe, Ward RA, Rao P: Blood-sucking mosquitoes of the subtribe Culisetina (Diptera, Culicidae) in world fauna, vol. 81: Citeseer; 1989.

53. Bisanzio D, Giacobini M, Bertolotti L, Mosca A, Balbo L, Kitron U, VazquezProkopec GMJP. Vectors: Spatio-temporal patterns of distribution of West Nile virus vectors in eastern Piedmont Region, Italy. Parasites Vectors. 2011:4(1):230

54. Hubálek Z, Halouzka JJEid: West Nile fever-a reemerging mosquito-borne viral disease in Europe. 1999, 5(5):643.
55. Medlock J, Snow K, Leach SJE. Infection: Possible ecology and epidemiology of medically important mosquito-borne arboviruses in Great Britain. Epidemiol Infect. 2007;135(3):466-82.

56. Paksa A, Sedaghat MM, Vatandoost H, Yaghoobi-Ershadi MR, MoosaKazemi SH, Hazratian T, Sanei-Dehkordi A, Oshaghi MA. Biodiversity of mosquitoes (Diptera: Culicidae) with emphasis on potential arbovirus vectors in East Azerbaijan province, northwestern Iran. J Arthropod Borne Dis. 2019;13(1):62.

57. Naseri-Karimi N, Vatandoost $H$, Bagheri M, Chavshin AR. Susceptibility status of Culex pipiens against deltamethrin and DDT, Urmia County, West Azerbaijan Province, northwestern Iran. Asian Pacific J Tropical Dis. 2015;5:S77-9.

58. Ghavami M, Ladonni H. The fauna and frequency of different mosquito species (Diptera: Culicidae) in Zanjan Province. Scientific Journal Zanjan University Medical Sci. 2005;13:46-54.

59. Banafshi O. ABAI MR, Ladonni H, Bakhshi H, Karami H, HAMIDIAN SA: The fauna and ecology of mosquito larvae (Diptera: Culicidae) in western Iran. Turkish J Zool. 2013;37(3):298-307.

60. Soleimani-Ahmadi M, Vatandoost H, Zare M. Characterization of larval habitats for anopheline mosquitoes in a malarious area under elimination program in the southeast of Iran. Asian Pacific J Tropical Biomed. 2014;4:S73-80

61. Nikookar SH, Azari-Hamidian S, Fazeli-Dinan M, Nasab SNM, Aarabi M, Ziapour SP, Enayati A. Species composition, co-occurrence, association and affinity indices of mosquito larvae (Diptera: Culicidae) in Mazandaran Province, northern Iran. Acta Trop. 2016;157:20-9.

\section{Publisher's Note}

Springer Nature remains neutral with regard to jurisdictional claims in published maps and institutional affiliations.
Ready to submit your research? Choose BMC and benefit from:

- fast, convenient online submission

- thorough peer review by experienced researchers in your field

- rapid publication on acceptance

- support for research data, including large and complex data types

- gold Open Access which fosters wider collaboration and increased citations

- maximum visibility for your research: over $100 \mathrm{M}$ website views per year

At BMC, research is always in progress.

Learn more biomedcentral.com/submissions 